\title{
Determinantes das Exportações de Castanha de Caju da Guiné-Bissau (1986-2011): uma análise sob a ótica do modelo de gravidade de Bergstrand ${ }^{1}$
}

\author{
Júlio Vicente Cateia ${ }^{2}$, Gilberto de Oliveira Veloso ${ }^{3}$ e Paulo Ricardo Feistel ${ }^{4}$
}

Resumo: Este trabalho analisa os determinantes das exportações de castanha de caju da Guiné-Bissau para a Índia no período de 1986-2011, utilizando o modelo de gravidade de Bergstrand (1985). Os resultados reportados do modelo de dados em painel (MQO-pooled) sugerem, por um lado, que o fluxo de exportações de castanha de caju é negativamente relacionado com o custo de transporte e, por outro, positivamente relacionado com a taxa de câmbio e rendas brutas e per capita, o que é consistente com os pressupostos teóricos dos modelos gravitacionais e com os estudos seminais da literatura econômica com a aplicação desses modelos.

Palavras-chaves: Exportações de castanha de caju, modelo de gravidade, Guiné-Bissau.

\begin{abstract}
This study analyzes the determinants of cashew nuts exports from Guinea-Bissau to India (1986-2011), by using the Bergstrand's (1985) gravity model. The reported results of the panel data model (OLS-pooled) suggest, on the one hand, that the flow of cashew nuts exports is negatively related to the transport cost and, on the other hand, positively related to the exchange rate and gross incomes and per capita incomes, which is consistent with the theoretical assumptions of gravity models and the seminal studies of the economic literature with application of these models.
\end{abstract}

Key-words: Cashew nuts exports, gravity model, Guinea-Bissau.

Classificação JEL: F14, Q11, Q17.

DOI: http://dx.doi.org/10.1590/1234-56781806-94790560403

1. Data de submissão: 13 de fevereiro de 2016. Data de aceite: 24 de fevereiro de 2018.

2. Universidade Federal do Paraná, Curitiba, Paraná, Brasil. E-mail: juliocateia@yahoo.com.br

3. Universidade Federal de Santa Maria, Santa Maria, Rio Grande do Sul, Brasil. E-mail: gilbertovel@gmail.com

4. Universidade Federal de Santa Maria, Santa Maria, Rio Grande do Sul, Brasil. E-mail: prfeistel@gmail.com 


\section{Introdução}

A Guiné-Bissau ${ }^{5}$ conquistou a sua independência política em 1973 e, desde então, desencadeou-se um processo de transformações socioeconômicas profundas visando não somente eliminar os traços do colonialismo, mas, sobretudo, promover o desenvolvimento das forças produtivas, o crescimento econômico e o progresso social (CÁ, 2008). Destarte, as políticas de desenvolvimento na primeira década que seguiu a independência foram direcionadas para a expansão e a diversificação das culturas agrícolas, cujo resultado foi a maior participação do primeiro setor na composição do PIB - 50\% em 1980 (WORLD BANK DATA, 2015) - e com um crescimento de $40 \%$ da produção de castanha de caju em 1979 em relação ao início da década (FAOSTAT, 2015).

Com o processo de abertura comercial iniciado em 1986, o comércio de castanha de caju passou a responder a elevação de seu preço internacional, marcando também o início de sua exportação para novos mercados, que deixou de dirigir para os tradicionais mercados europeus e passou a ser direcionada para os mercados asiáticos, tais como Hong Kong, Singapura e Índia. A partir deste período, a Índia tornou-se o prin-

5. A Guiné-Bissau fica situada na costa da África Ocidental, banhada pelo oceano Atlântico. Ao norte faz a fronteira com o Senegal, ao sudoeste e a leste, pela Guiné-Conacri e ao sul e a oeste, pelo oceano Atlântico. O país é formado por oito regiões e tem superfície total de $36.125 \mathrm{~km}^{2}$, com altitude que atinge a máxima de 300 metros acima do nível do mar. cipal parceiro comercial da Guiné-Bissau com participação superior a $86 \%$ (WITS, 2015), e a castanha de caju responde por mais de $90 \%$ das exportações guineense destinadas para o mercado indiano (GUINÉ-BISSAU, 2005).

Atualmente, a Guiné-Bissau desempenha importante papel no mercado mundial de castanha de caju com a parcela no comércio crescendo de 5\% em 1986, para $12 \%$ em 2011, tornando-se, assim, o segundo exportador mundial nesse último ano, com receita de US\$ 203.750 milhões, atrás apenas da Costa do Marfim, com receita de US\$ 263.592 milhões (FAOSTAT, 2015).

Em função deste crescimento do país, tanto na produção quanto no comércio, cresce também a dependência interna com relação às atividades ligadas à exploração do caju. Estudo recente de Barry et al. (2009) mostra que o grau de dependência da economia guineense em relação à exportação de castanha de caju ultrapassa até mesmo a dependência da maioria dos países membros da Opep em relação às exportações de petróleo, uma vez que mais de $98 \%$ das receitas das exportações e $17 \%$ das receitas fiscais são derivadas dessa cultura (KYLE, 2009).

Diante disso, o presente estudo busca utilizar um modelo de gravidade visando aprofundar um entendimento de como a exportação de castanha de caju é influenciada por variáveis, tais como os tamanhos dos mercados, as estruturas produtivas, os preços e os custos de transporte. Essas variáveis recorrentemente aparecem na literatura sobre comércio internacional e o entendimento de sua magnitude pode ajudar as autoridades a definir a política comercial de acordo 
com a realização do setor exterior. Além disso, um entendimento adequado da natureza mutável ou estática dos fatores que influenciam as exportações de castanha de caju guineense pode servir de estratégia para o país em termos de adoção de medidas para aperfeiçoar sua inserção, visando aproveitar os ganhos do comércio.

O principal avanço da presente pesquisa ocorre em duas direções. Primeiro, a utilização dos modelos de gravidade como instrumento de análise de fluxos comerciais é muita ampla e é comum encontrar estudos neste sentido em economias desenvolvidas ou com estruturas produtivas diversificadas (AITKEN, 1973; CASTILHO, 2002; e outros) e também em economias em desenvolvimento (ZARZOSO e LEHMANN, 2003; BIKKER, 2009; EL-ARISH, 2012; FARIAS e HIDALGO, 2012). A Guiné-Bissau é um país de baixo nível de desenvolvimento e, portanto, com a estrutura produtiva pouca diversificada, sendo fortemente dependente de alguns subsetores ou produtos específicos, como é a castanha de caju, de modo que choques externos podem fortemente afetar a sua demanda, transmitindo efeitos para a economia como um todo. Portanto, o primeiro avanço reside basicamente em analisar um produto com peso significativo na composição da grade exportadora e do PIB tendo como instrumento um modelo gravitacional que considera a heterogeneidade existente entre os setores da economia. Segundo, apesar da importância de castanha de caju para a economia guineense, não foram encontrados estudos com o propósito de analisar especificamente o comércio bilateral desse produto em Guiné-Bissau. A consecução deste projeto pode preencher esta lacuna teórica.

Frente a isso, o estudo busca responder à seguinte questão: quais são os principais fatores que influenciam o comércio bilateral de castanha de caju da Guiné-Bissau?

Para responder esta pergunta, este trabalho tem como objetivo geral analisar os determinantes das exportações de castanha de caju da Guiné-Bissau para a Índia no período de 1986-2011.

Especificamente, busca-se contextualizar a relação comercial entre a Guiné-Bissau e Índia; analisar o papel de castanha de caju para o desenvolvimento guineense; e avaliar a sensibilidade de exportações de castanha de caju às variações dos parâmetros das rendas da Guiné-Bissau e da Índia, da taxa de câmbio e dos custos de transporte.
O estudo está estruturado em seis seções, além da seção introdutória. A seção 2 destina-se a apresentar o referencial teórico e a revisão de literatura sobre os modelos gravitacionais. A seção 3 é voltada para descrever o modelo a estimar. Uma análise do setor agrícola guineense é feita na seção 4 . A seção 5 discute os resultados do modelo estimado, e as conclusões são apresentadas na seção 6 .

\section{Modelo de Gravidade de Comércio: uma revisão teórica e da literatura}

Os modelos gravitacionais têm uma longa história de utilização nas ciências sociais (WALL, 1999) e sua origem nesse campo de conhecimento é geralmente associada ao movimento científico e/ou intelectual do final do século XIX, conhecido como a "física social", cuja ideia principal era encontrar uma explicação empírica para os fenômenos da sociedade, como tem sido o êxito da física em explicar os fenômenos da natureza (STEWART, 1948). Por isso, segundo Coelho (1983, p. 1), os modelos gravitacionais foram inicialmente deduzidos por analogia com a Lei Gravitacional de Newton e encarados como modelos puramente descritivos.

Deardorff (1998) comenta que a aplicação dos modelos de gravidade em economia remonta os estudos pioneiros de Tibergen (1962), Linnemann (1967), Geraci e Prewo (1977). A partir de então estes se popularizaram e tornaram-se um instrumento empírico muito utilizado para este propósito (BRADA e MÉNDEZ, 1985; SANSO et al., 1993; HARRIS e MÁTYÁS, 1998; EICHENGREEN e IRWIN, 2000; POLDER e MEIJEREN, 2000; FEENSTRA et al., 2001).

\subsection{Modelo de gravidade de Bergstrand (1985)}

O modelo de Bergstrand (1985) é um modelo gravitacional e normalmente é utilizado para fluxo desagregado de exportações. Por um lado, uma função de utilidade com a elasticidade de substituição constante (CES) é representada para os consumidores do país importador $j$, de tal maneira que:

$$
U_{j}=\left\{\left[\left(\sum_{k=1}^{N} x_{k j}^{\theta_{j}}\right)^{\frac{1}{\theta_{j}}}\right]^{\psi_{j}}+x_{j j}^{\psi_{j}}\right\}^{\frac{1}{\psi_{j}}}, k \neq j ; j=1,2, \ldots, N
$$


586 - Determinantes das Exportações de Castanha de Caju da Guiné-Bissau (1986-2011): uma análise sob a ótica do modelo de gravidade de Bergstrand

Em que $X_{k j}$ é o volume de $k$ produtos agregados demandados por esses consumidores. No nosso caso, $X_{k j}$ representa tão somente o volume de castanha de caju da Guiné-Bissau demandado pelos consumidores da Índia. A quantidade consumida do produto no mercado indiano depende basicamente do nível de utilidade que tem seus consumidores; $\psi=\left(\omega_{j}-1\right) / \omega_{j}$, sendo $\omega_{j}$ a CES entre produtos domésticos e importados em $j$, ou seja, é o quanto consumir uma unidade adicional de castanha de caju leva ao consumidor na Índia a deixar de consumir outros produtos substitutos; e $\theta_{j}=\left(\sigma_{j}-1\right) /$ $\sigma_{j}$, em que $\sigma_{j}$ é a CES entre importáveis em $j$ (ou seja, é a elasticidade de substituição entre os bens não produzidos no mercado $j$, mas vendidos nesse mercado - são importações da Índia). Em geral, assume-se que $0 \leq$ $\omega_{j} \leq \infty$ e $0 \leq \sigma_{j} \leq \infty$.

Por outro, supondo que as firmas adotam o comportamento maximizador em cada país (isto é, os produtores de castanha de caju na Índia e na Guiné-Bissau procuram maximizar o lucro ou minimizar os custos de sua produção), a função de maximização é representada através da seguinte equação:

$$
\prod_{i}=\sum_{k=1}^{N} p_{i k} x_{i k} W_{i} Q_{i}, \quad i=1,2, \ldots, N
$$

Em que $Q_{i}$ é o montante disponível de recurso, assumido como o único que circula internacionalmente para produzir vários produtos; $W_{i}$ é o valor em moeda local do país $i$ de uma unidade de $Q_{i}$. Bergstrand (1985) argumenta que $Q$ é alocado em cada país de acordo com a elasticidade de transformação constante (CET), representado por:

$$
Q_{i}=\left\{\left[\left(\sum_{k=1}^{N} X_{i k}^{\phi_{i}}\right)^{\frac{1}{\phi_{i}}}\right]^{\delta_{i}}+x_{i i}^{\delta_{i}}\right]^{\frac{1}{\delta_{i}}}, \quad i=1,2, \ldots, N
$$

$\delta_{i}=(1+\eta \mathrm{i}) / \eta_{i}$, em que $\eta_{i}$ é a CET de $i$ entre a produção para o mercado doméstico e produção para o mercado estrangeiro. Ou seja, como há perfeita substituibilidade na produção, $\eta_{i}$ indica quanto os produtores de um país vão deixar de produzir para exportação se destinar uma unidade adicional de sua produção para o mercado interno; $\varnothing_{i}=\left(1+\varphi_{i}\right) / \varphi_{i}$, $\varphi_{i}$ é CET de $i$ para produção entre mercados exportadores, isto é, entre os países produtores para exportação. Também $0 \leq \eta_{i} \leq \infty$ e $0 \leq \varphi_{i} \leq \infty$.

Admitindo a igualdade entre as elasticidades e que ambas sejam também iguais a infinito, o modelo se reduz à seguinte expressão:

$$
P X_{i j}=(1 / 2) Y_{i}^{1 / 2} Y_{j}^{1 / 2}
$$

Em que $P X_{i j}$ é fluxo de exportações do país $i$ para o país $j$; e $Y_{i}$ e $Y_{j}$ são as respectivas variáveis de atração ao comércio.

Esta é a essência do modelo de Bergstrand (1985). A intuição é a de que a equação gravitacional é uma forma reduzida de um subsistema de quatro equações de equilíbrio parcial derivado de um modelo de comércio de equilíbrio geral com diferenciação de produtos por lugar de origem (BERGSTRAND, 1985, p. 475). É um modelo que é a extensão da equação gravitacional padrão, mas fundamentado na teoria de comércio internacional desenvolvida considerando as estruturas de mercados perfeitos.

Os modelos de gravidade aumentados ou estendidos (ver OGULEDO e MACPHEE, 1994) têm sido utilizados para análise de comércio desagregado, tendo obtido resultados bastante robustos. Por exemplo, Hatab et al. (2010) aplicaram o modelo de gravidade para analisar os principais fatores que influenciam as exportações agrícolas do Egito para seus principais parceiros comerciais (1994-2008). O trabalho mostrou que um aumento de $1 \%$ nas respectivas rendas brutas do Egito e de seus parceiros comerciais provocaria uma elevação de $0,74 \%$ e $5,73 \%$ no comércio bilateral de produtos agrícolas daquele país. Por outro lado, um aumento no custo de transporte e uma elevação ou queda cambial em $1 \%$ resultariam na baixa de tal fluxo em $-1,11 \%$ e $-0,039 \%$, respectivamente. As rendas per capita do país exportador e importador também apresentam os respectivos coeficientes negativos de $-0,81 \%$ e $-5,781 \%$. A conclusão do estudo é que os resultados reportados pelo modelo são importantes para a formulação de políticas comerciais visando promover as exportações agrícolas do Egito para o mercado mundial.

Já Zhu e Gu (2008) aplicaram a equação gravitacional para avaliar o efeito fronteira do comércio de produtos agrícolas China-EUA (2005), através dos dados em painel. Segundos eles, os efeitos fronteira da ChinaEUA influenciam o comércio desses produtos e são bem explicados através do modelo de gravidade log-linear para fluxos desagregados.

Em seu estudo, Sevela (2002) utilizou a equação de gravidade para descrever os fluxos comerciais bilaterais da República Checa (1999-2001). O estudo apontou que a renda nacional bruta, a renda nacional per 
capita e a distância geográfica entre as capitais dessas economias foram estatisticamente significativas a $5 \%$. Evidenciou-se que havia alta correlação positiva entre o volume de exportação de determinados grupos de commodities, tais como alimentos e animais vivos, e o rendimento nacional bruto, mas a correlação entre exportação de produtos agros e renda nacional bruta per capita e a distância geográfica era negativa.

Enquanto isso, Baier e Bergstrand (2007) utilizaram a equação gravitacional objetivando fornecer uma análise empírica do efeito da Área de Livre Comércio (ALC) sobre o comércio bilateral de 96 parceiros comerciais $(1960,1965, \ldots, 2000)$. Para esses autores, a formação da ALC teria o impacto de $0,29 \%$ de aumento do fluxo de comércio dos países membros, enquanto que a alta $1 \%$ das rendas dos países exportadores resultaria em aumento de 1,18\% no comércio bilateral em 2000. Uma alta de $1 \%$ da renda do país importador intensificaria o comércio entre os países da ALC com seus parceiros em até $0,98 \%$ em 2000; porém, tal comércio teria redução de $1,17 \%$ se o custo de transporte aumentasse ou caísse em $1 \%$.

\section{Metodologia}

Esta seção destina-se a apresentar o modelo de gravidade para estimar o comércio bilateral de castanha de caju da Guiné-Bissau e os procedimentos econométricos.

\subsection{Modelo econométrico gravitacional}

Para fins de estimação, a Equação (4) normalmente é linearizada e estimada em sua forma log-linear, adicionando as variáveis de resistência, a constante de proporcionalidade e o termo de erro. Assim,

$$
\begin{aligned}
& \ln (\text { exp ort })=\alpha_{0}+\alpha_{1} \ln (\text { pibgb })+ \\
& +\alpha_{2} \ln (\text { pibind })+\alpha_{3} \ln (\text { pibpergb })+ \\
& +\alpha_{4} \ln (\text { pibperind })-\alpha_{5} \ln (\text { dist })+\alpha_{6} A_{G I}+U_{G I K}
\end{aligned}
$$

Em que lnexport é o logaritmo natural dos fluxos de exportações de castanha de caju da Guiné-Bissau para a Índia; lnpibgb e lnpibind são os logaritmos naturais das rendas brutas da Guiné-Bissau e da Índia, respectivamente; Inpibpergb e lnpibperind são os seus respectivos logaritmos naturais das rendas per capita; Indist é a distância entre os centros comerciais da Guiné-Bissau e da Índia; $A_{G I}$ é uma constante de proporcionalidade indicando a existência ou não de algum acordo de comércio entre Guiné-Bissau e Índia; e $U_{G l k}$ é o termo de erro log-normalmente distribuído com o primeiro momento nulo, isto é, $E\left(U_{G I k}\right)=0$.

Como não foi encontrado nenhum acordo de comércio entre os dois países e levando em consideração o fato de que os preços podem não se ajustar somente para igualar às condições da oferta e da demanda, mas também que influenciam o volume de exportações de produtos específicos, o modelo (5) é acrescido de um vetor de preços relativos e a equação resultante é representada da seguinte forma:

$$
\begin{aligned}
& \ln (\text { exp ort })=\phi_{0}+\phi_{1} \ln (\text { pibgb })+ \\
& +\phi_{2} \ln (\text { pibind })+\phi_{3} \ln (\text { pibpergb })+ \\
& +\phi_{4} \ln (\text { pibperind })-\phi_{5} \ln (\text { dist })+ \\
& +\phi_{6} \ln (\text { cambio })+U_{G I K}
\end{aligned}
$$

Em que lncambio é o logaritmo natural da taxa de câmbio.

As variáveis rendas brutas e rendas per capita são de atração ao comércio e, teoricamente, devem ter sinais positivos; enquanto a distância utilizada como a proxy do custo de transporte é uma variável de resistência ao comércio e, assim, seu coeficiente deve ser negativo. Ademais, quando a taxa de câmbio aumenta, diz-se que há depreciação (apreciação) da moeda do país exportador (importador). Uma depreciação, portanto, sugere que a Guiné-Bissau está aumentando suas exportações para a Índia, ceterisparibus, de tal forma que, se essa taxa tende ao infinito, implica que o volume de exportações está aumentando indefinidamente. Por outro lado, se a taxa de câmbio tende a zero, as exportações são insignificantes. Portanto, $\alpha_{6}$ depende se a taxa de câmbio é ou não valorizada.

\subsubsection{Abordagens Eeconométricas}

O modelo de gravidade aqui representado é estimado com base nos dados em painel porque, por um lado, a equação gravitacional é geralmente estimada com este tipo de dados e, por outro, segundo Greene (1993, p. 284), a principal vantagem de dados em painel é que eles permitem ao pesquisador grande flexibilidade em modelar diferenças no comportamento entre os indivíduos e também fornecem um ambiente 
588 - Determinantes das Exportações de Castanha de Caju da Guiné-Bissau (1986-2011): uma análise sob a ótica do modelo de gravidade de Bergstrand

extremamente rico para o desenvolvimento de técnicas de estimação e de análise de resultados teóricos (ver também HSIAO, 2003).

A técnica comum mais utilizada para a análise de dados em painel refere-se às abordagens de Efeitos Fixos (FE, fixedeffects) e Efeitos Aleatórios (RE, randomeffects) ou também o método pooled (GUJARATI e PORTER, 2011, p. 537-604).

Segundo Cheng e Wall (2005, p. 5), o modelo pooled impõe a restrição adicional sobre o modelo geral de que o vetor de parâmetros é o mesmo para todos os indivíduos ou grupos, embora normalmente permita que os interceptos sejam diferentes ao longo do tempo.

Stock e Watson (2004, p. 190) mostram que a regressão com FE é um método adequado para controlar as variáveis omitidas em dados de painel quando elas variam entre indivíduos, mas constantes ao longo do tempo em análise; pode também ser utilizada quando há duas ou mais observações temporais para cada indivíduo.

Greene (1993) afirma que, se os efeitos individuais não observados forem estritamente não correlacionados com os regressores, é melhor modelar os termos constantes específicos individuais como aleatoriamente distribuídos entre unidades de cross-section. A regressão de RE é um método para controlar as heterogeneidades aleatórias específicas do grupo e constantes ao longo do tempo e não admite a correlação dos efeitos individuais não observados com regressores.

Há, contudo, alguns problemas associados aos métodos pooled, FE e RE. Cheng e Wall (2005, p. 5) comentam que a estimação do modelo de gravidade de comércio utilizando o modelo pooled pode fornecer estimativas tendenciosas, porque o comércio é influenciado por muitos outros fatores não observados e associados às características dos países e que podem efetivamente influenciar as estimativas.

Segundo Kokko e Tingvall (2000), as preferências do país variam muito pouco no tempo e, assim, utilizar os FE significa estimá-las com erros padrão grandes. Além disso, como a distância é também uma variável do modelo invariante no tempo, utilizar as regressões de efeitos fixos é o mesmo que ignorar os efeitos dessa variável na sua explicação, embora os estimadores de FE permitam manter variáveis invariantes no modelo com número de regressores suficientes.

Enquanto isso, a suposição do modelo de RE segundo a qual os efeitos individuais não observados são não correlacionados com os regressores não tem justificativa forte. Greene (1993) argumenta que, em caso de os regressores terem alguma correlação com efeitos individuais não observados, o tratamento de RE pode sofrer com inconsistência.

Em função da limitação que cada método apresenta, a presente pesquisa opta, inicialmente, em realizar os testes usuais (F/Chow, multiplicador de Lagrange e Hausman), que nos indicam a melhor abordagem a utilizar como instrumento para análise dos resultados.

O teste Chow é utilizado para a escolha entre a regressão com o modelo pooled e a regressão com o modelo de FE. Neste procedimento, quanto mais a estatística do teste se aproxima de uma unidade, maior é a probabilidade de não rejeitar a hipótese nula de que o melhor modelo de dados em painel seja o pooled. $\mathrm{O}$ Teste LM é utilizado para a escolha entre os modelos pooled e de RE. Diz-se que o pooled é escolhido em detrimento do modelo de RE quando a estatística do teste tende a uma unidade, ou seja, quando não se rejeita a hipótese nula de que o pior modelo seja o de RE. Por fim, utiliza-se o teste de Hausman para efetuar a comparação entre os modelos de FE e RE, sob a hipótese nula de que o segundo seja melhor que o primeiro.

Para analisar a hipótese de ausência de autocorrelação serial e da heteroscedasticidade do modelo, recorre-se aos testes de autocorrelação e heteroscedasticidade dos resíduos indicados pela literatura. Entre os testes mais sugeridos para analisar a autocorrelação serial quando se trata de dados em painel, o de Wooldridge é recorrentemente utilizado. Este teste assume a hipótese nula de que as séries do modelo em painel sejam não autocorrelacionadas de primeira ordem, enquanto a hipótese alternativa é de que há autocorrelação serial de primeira ordem no modelo.

Com relação à heteroscedasticidade, os testes mais recorrentes são os de Goldfeld-Quandt, Gujarati e Porter (2011, p. 386), Park, Gujarati e Porter (2011, p. 383), e o teste geral de White, Gujarati e Porter (2011, p. 391). Também é cada vez mais utilizado o teste de Breusch-Pagan/Cook-Weisberg para verificar se a variância do erro não apresenta comportamento explosivo. Opcionalmente, foi escolhido testar a hipótese nula de homoscedasticidade utilizando os testes de White e de Breusch-Pagan/Cook-Weisberg.

Ademais, utiliza-se o Fator de Inflação de Variância (FIV) para detectar o grau da multicolinearidade. 
O inverso do FIV é chamado de fator de tolerância (TOL): quanto mais este tende a zero, mais alta é a colinearidade entre as variáveis independentes. Gujarati e Porter (2011, p. 347) comentam que a presença de uma relação linear perfeita entre os regressores ao tornar a variância e covariância muito grande pode fazer com que os intervalos de confiança sejam amplos e os estimadores de MQO, mais sensíveis a alterações nos dados.

\subsection{Fonte e tratamento de dados}

O processo de estimação da equação (6) envolve a utilização de sete (7) variáveis: lnexport $\equiv$ volume de exportações de castanha de caju (em US\$); $\operatorname{lnpibg} b \equiv$ renda bruta da Guiné-Bissau (em US\$); Inpibind $\equiv$ renda bruta da Índia (em US\$); $\operatorname{lnpibpergb~} \equiv$ renda per capita da Guiné-Bissau (em US\$); Inpibperind $\equiv$ renda per capita da Índia (em US\$); Indist = distância entre Guiné-Bissau e Índia; e lncambio $\equiv$ taxa de câmbio (em US\$).

Os dados da pesquisa foram coletados a partir de fontes variadas e de fácil acesso. As quantidades exportadas de castanha de caju da Guiné-Bissau têm como fonte o Fundo da Organização para Alimentação e Agricultura das Nações Unidas (FAO), a partir da sua base de dados Faostat <Agricultural Trade> e são do ano civil.

Os dados anuais das respectivas rendas brutas e rendas per capita da Guiné-Bissau e da Índia foram obtidos junto à base de dados $<$ WORLD BANK DATA $>$ do Banco Mundial (BM).

Os dados da taxa de câmbio são do Banco Central dos Estados da África Ocidental (BCEAO) e expressam a relação dólar americano/Franco CFA (moeda de Guiné-Bissau).

A definição da distância como Proxy de custos de transporte varia de estudo para estudo. No caso presente, considerou-se a distância entre os portos de embarque localizados nas cidades capitais da GuinéBissau e da Índia. Este dado é obtido no United States Department of Agriculture (USDA).

Cabe ressaltar que todas as séries do modelo são de frequências anuais e estimadas em logaritmos. $\mathrm{O}$ processo de estimação consiste na utilização de um programa: Stata 2010 (licenciado para o Departamento de Ciências Econômicas da Universidade Federal de Santa Maria - UFSM).

\section{Setores comercial e agrícola da Guiné-Bissau e a castanha de caju}

A Guiné-Bissau integra-se no grupo dos países menos avançados em função do desempenho relativamente baixo da sua economia que apresentava, em 1986, um PIB de apenas US\$ 503 milhões (UNCTAD, 2015) e que refletia o atraso técnico de seus setores. Entretanto, um dos traços mais marcantes no processo de desenvolvimento econômico do país a partir da década de 1980 refere-se, por um lado, à crescente inserção internacional de sua economia e, por outro, à dependência desta para com a castanha de caju, que passou a ser produzida e exportada em grande quantidade não apenas para os tradicionais mercados europeus, mas também para novos mercados consumidores em decorrência da reestruturação do setor comercial. Esta seção busca apresentar um preâmbulo dos setores agricultura e comércio da Guiné-Bissau depois do programa de reajustamento estrutural que proporcionou maior comércio internacional dos produtos do primeiro setor e, particularmente, de castanha de caju.

\subsection{Breve história do processo de desenvolvimento da economia da Guiné-Bissau}

Com o crescimento da consciência do relativo atraso em que o país se encontrava em relação aos seus vizinhos que, em sua maioria, são ex-colônias britânica e francesa, as políticas de desenvolvimento na primeira década após a independência em 1973 de Guiné-Bissau foram direcionadas para a introdução de novos produtos e modernização do setor agrícola (vantagens comparativas), visando promover a participação desse setor na composição do valor adicionado doméstico e promover as novas culturas (CÁ, 2008).

Entre as principais produções no período anterior a 1986 destacavam-se o amendoim e óleo de palma, e o comércio interno desses produtos era concentrado nas grandes cidades e, conforme Mendes e Jawad (1986), os principais parceiros comerciais da GuinéBissau eram os países extracontinentais, dos quais Portugal detinha uma parcela maior. Para esses autores, a característica da rede do comércio guineense no pós-independência era marcada por uma larga coexistência de um setor público preponderante e de pequenos comerciantes privados, devido ao fato de a 
590 - Determinantes das Exportações de Castanha de Caju da Guiné-Bissau (1986-2011): uma análise sob a ótica do modelo de gravidade de Bergstrand

centralização das decisões iniciada logo após a independência ter dado início à estatização das empresas que operavam no mercado doméstico, como a Gouveia (a empresa de então Guiné portuguesa), e à nacionalização da empresa Ultramarina (a principal empresa exportadora), transformando-a em Socomin, resultando em um monopólio estatal do comércio externo e interno dessas duas empresas.

Particularmente no que tange ao comércio exterior, as principais exportações do período eram predominantemente de produtos agrícolas, sendo que todos os produtos manufaturados eram oriundos do exterior, explicando, assim a evolução do balanço de pagamentos, que apresentava um déficit de US\$ 67 milhões em 1985, incompatível com o tamanho da economia, pois o PIB de 1985 era de apenas US\$ 455 milhões (UNCTAD, 2015).

A evolução desfavorável das contas externas conjugadas à seca de 1983 que atingiu toda a área rural do país, afetando grandemente a produção, levaram à adoção de medidas de estabilização em 1983/84, visando reforçar a modernização do primeiro setor e reestruturar as atividades do comércio (SANHÁ, 1988). A modernização se daria mediante os programas do governo de financiamento aos agricultores e de importação de máquinas e equipamentos que seriam utilizados na produção agrícola. Todavia, na ausência de instituições financeiras, tanto o financiamento das importações de máquinas e equipamentos e de itens associados quanto o de pequenos agricultores se dariam através de empréstimos externos que, por sua vez, agravavam déficits no balanço de pagamentos na ordem de $26 \%$ do PIB em 1986 (WORLD BANK DATA, 2015).

Em verdade, a reestruturação das atividades do comércio era motivada pela situação em que se encontrava o setor comercial no período e tinha por objetivo principal dar a este setor um papel importante no processo de desenvolvimento do país, implicando, assim, em uma transformação dos órgãos públicos, tais como as empresas públicas, o ministério de comércio e turismo, dando maior espaço à operação dos agentes privados (SANHÁ, 1988). As empresas públicas passaram a ter responsabilidades diferentes, mas ainda funcionando dentro das regras estabelecidas pelo governo central. A Armazém do Povo se especializou na coleta e exportação de produtos nacionais de diferentes setores, enquanto a Socomin era responsável principalmente pela prestação de serviços. Segundo Sanhá (1988), não obstante os impactos positivos dessas medidas, em particular ao nível do setor agrícola e, consequentemente, ao nível das exportações, a situação econômico-financeira viria a sofrer, a partir de 1985, uma acentuada deterioração, levando à adoção do programa de reajustamento estrutural, o qual permitiu a expansão do comércio exterior guineense.

\subsubsection{Programa de reajustamento estrutural}

O Programa de reajustamento estrutural (PAE) fazia parte de um conjunto de medidas criadas em Bretton Woods e concebidas para auxiliar em países com problemas conjunturais em seu balanço de pagamentos e na gestão das contas estatais. Isto porque, em 1986, a economia guineense vivia uma das suas maiores crises pós-independência em decorrência principalmente do persistente desequilíbrio entre a demanda por produção e a oferta da produção (SANHÁ, 1988). Esta situação pode ser analisada à luz da situação econômica do período.

a) Situação externa: a demanda interna expandiu exponencialmente em função do fim do conflito que permitiu o crescimento da população a taxas superiores a $22 \%$ ao ano entre 1973 e 1985. Nesse período, a receita obtida com a produção agrícola, que havia atingido US\$ 72.355 milhões em 1973, somente cresceu para US\$ 115.929 milhões em 1985 (FAOSTAT, 2015). Assim, o aumento do consumo interno, que alcança 10\% do PIB em 1986, não compensado pela elevação da produção, teve como resultado principal o aumento das importações não compensado pelo quantum exportado, gerando aumento do endividamento externo para fazer frente aos problemas do balanço de pagamento e o consequente agravamento da vulnerabilidade externa.

b) Déficit do setor público: dada a dependência da receita do setor público em relação às divisas decorrentes da exportação de produtos agrícolas, o baixo crescimento das exportações agregadas de 1973 a 1986 agravava a situação financeira do Estado. Somou-se a isto a crise do setor agrícola, em 1983/1984, que provocou aumento da demanda por emprego público e elevou a despesa salarial. 
Em decorrência dessas crises, que refletiam nos objetivos de superação do subdesenvolvimento, foi lançado em 1986 um programa de reajuste estrutural que abrangia as reformas em diferentes áreas e era baseado em três fases distintas e mutuamente dependentes, quais sejam: (i) estabilização, (ii) crescimento e (iii) crescimento autossustentado (PADOVANI, 1991; TVEDTEN, 1991).

Na primeira fase buscava-se realizar as principais reformas estruturais, de modo a eliminar os persistentes desequilíbrios macroeconômicos. Entre os objetivos destacam-se (i) a redução no médio prazo da vulnerabilidade externa, mediante a progressiva geração do superávit na conta corrente, sendo prevista uma redução do déficit nesta rubrica na ordem de 5,4\% para o ano de 1987 em relação ano anterior; (ii) redução do déficit público ao nível compatível com o crescimento do produto na ordem de 37\% em 1986 para $17 \%$ em 1987. Para alcançar este resultado, os investimentos públicos nas áreas não prioritárias, que abrangiam a comercialização e exportação de mercadorias, seriam reduzidos na ordem de $16 \%$; e (iii) incentivo ao aumento da capacidade produtiva através da modernização do setor agrícola. Adicionalmente, em função dos excessivos gastos e do aumento da emissão monetária na primeira metade dessa década, o país vivia uma das suas primeiras crises inflacionárias. Em 1986, após crescimentos relativamente estáveis, a taxa de inflação registrava a sua alta histórica da ordem de $45 \%$ ao ano. Neste contexto de estabilização, ficou determinado um "tratamento de choque" à inflação, que seria reduzida para 25\% ao ano em 1987 (SANHÁ, 1988).

Em relação às reformas do setor financeiro, vale notar que o Banco Central guineense era encarregado da política monetária logo após a independência. Anos depois, em meados da década de 1980, foi criado o Banco Internacional da Guiné (BIG), tornando-se o maior banco privado nacional, "com dois escritórios em Bissau e sucursais em Bafatá e Gabú, no leste do país, e em Canchungo, no norte" (CÁ, 2008, p. 173). Esse banco, junto ao Banco Central, fazia parte das instituições que formavam o sistema financeiro guineense; ademais eram bancos portugueses ou instituições financeiras estrangeiras.

Alcançados os objetivos da primeira fase, a fase seguinte seria a de medidas voltadas ao crescimento econômico. Ficou previsto para o ano de 1987 um crescimento do produto de $5,7 \%$, contra $4,2 \%$ de
1986. Os financiamentos dos programas desta fase viriam de uma parceria entre o governo da GuinéBissau e o Banco Mundial (BM), Fundo Monetário Internacional (FMI) e outras instituições e países, tais como Confederação Helvética, países baixos e Arábia Saudita. Tanto nessa fase como nas outras duas, o BM seria a instituição responsável em conceder o montante de financiamento para a consecução dos projetos. Assim, dos quase US\$ 42 milhões do montante de financiamento obtido no período de 1987/1988, US\$ 19 milhões correspondiam ao financiamento concedido pelo BM e seus gabinetes de apoio ao desenvolvimento dos países africanos (SANHÁ, 1988). Por outro lado, dada a crescente demanda pelos recursos do FMI às necessidades especiais dos países em desenvolvimento, o montante disponibilizado por aquela instituição ao programa de reajustamento estrutural da Guiné-Bissau era de apenas US\$ 1,9 milhão, além de US\$ 11,80 milhões provenientes do Banco Africano de Desenvolvimento (BAD) através de um fundo destinado para atender aos programas de desenvolvimento dos países continentais. Entretanto, uma vez verificada a insuficiência desses recursos, cabe ao governo acentuar as negociações com seus credores externos a fim de obter o montante necessário para viabilizar os objetivos propostos. A Suíça concedeu cerca de US\$ 5,96 milhões, enquanto o financiamento da Arábia Saudita ao programa era de US\$ 3,21 milhões.

Com base nas fases anteriores, o país engendraria, a partir de 1992, ritmos de crescimento econômico autossustentados, mobilizando também esforços para promover as políticas sociais. O principal objetivo nessa fase era de fomentar um desenvolvimento econômico endógeno, que diminuiria a dependência do país com o exterior. Para tanto, acreditava-se que era preciso aperfeiçoar a tecnologia da produção agrícola que possibilitaria o aumento da produção para atender à demanda doméstica e à exportação, de modo a gerar divisas provenientes, sobretudo, dos impostos de exportações e que teriam duplas funções, a saber: (i) seriam realocadas no combate à pobreza e (ii) evitariam o constrangimento externo, à medida que são destinadas para saldar os compromissos externos e, com isso, diminuem a demanda por empréstimos externos e internos.

Para alcançar os objetivos propostos, iniciou-se a reforma cambial em 1987, que foi levada a cabo no começo da década de 1990, quando o governo adotou 
592 - Determinantes das Exportações de Castanha de Caju da Guiné-Bissau (1986-2011): uma análise sob a ótica do modelo de gravidade de Bergstrand

taxas múltiplas de câmbio. Segundo Cá (2008), "havia uma taxa de câmbio oficial, que seguia de perto a taxa de mercado livre, calculada como uma média da taxa observada nas agências de mercado cambial e nos operadores informais livres no mercado" (p. 172). A segunda taxa de câmbio era aquela das agências de mercado livre.

Depois da implementação do PAE, surgem estudos avaliando seu impacto em diferentes setores. Por exemplo, segundo Sanhá (1988), a adoção de dois tipos de câmbio, ao contribuir para aumentar o comércio internacional dos produtos do país, traduzia-se em uma redução do déficit em transações correntes de $8 \%$ em 1987 em relação ao ano anterior.

Entretanto, sem ter conseguido estruturar suficientemente seu sistema econômico na década de 1980, o país inseriu-se no mercado internacional com fortes desequilíbrios nas contas externas, o que exigia a demanda por empréstimos para saldar a sua dívida e até para pagamento de funcionários públicos. Tal demanda superava as divisas de exportações, anulando, assim, o efeito de melhoria na conta de balança comercial associada grandemente ao crescimento de $100,75 \%$ da produção para exportação de castanha de caju em 1992 em relação a 1986 (FAOSTAT, 2015). Segundo Padovani (1991), o insucesso das medidas de reajuste estrutural, em função dos termos de troca dos produtos agrícolas que permaneceram numa situação desfavorável, chegou a provocar até o quase esgotamento das reservas internacionais do país e, em decorrência do descontrole orçamentário e monetário, precipitou-se a primeira alta descontrolada da inflação.

Alvesson e Zeján (1991) analisaram os efeitos do PAE sobre as mudanças do bem-estar dos pequenos proprietários rurais na região de Catió, que é uma das principais produtoras de arroz da Guiné Bissau. O estudo foi realizado por meio de 67 entrevistas em 25 aldeias, envolvendo a percepção dos pequenos produtores relativamente a mudanças de preços relativos, aumento da oferta de bens de consumo básicos e de bens de investimento. Para eles, o aumento de oferta de bens consumo para a população rural de Catió é um indício de que houve uma sensível melhoria do bem-estar, apesar da análise feita não sugerir melhoria ou deterioração nos termos de troca. Para Tvedten (1991), contudo, o PAE prejudicou fortemente a situação socioeconômica da população do litoral em função do aumento do custo de vida e da queda do comércio de produtos agrícolas.

Não obstante, na década de 1990, o país passou por dois momentos marcantes e extremamente correlatos que refletiram profundamente no seu processo de desenvolvimento socioeconômico. O primeiro foi a transição de um regime político em que havia apenas um único partido no poder desde a independência, em 1973, para outro regime mais difuso em termos partidários. Esta transição, embora fundamental para a realização da eleição presidencial em 1994, gerava a instabilidade político-institucional em decorrência do surgimento de partidos da oposição e dos movimentos sociais, que reivindicavam as condições existentes, levando ao esquecimento dos programas iniciados na década anterior. O segundo momento, não estritamente independente do primeiro, foi o Conflito Civil de 1998, que trouxe consequências profundas à economia nacional, ao provocar a paralisação de qualquer programa de desenvolvimento. Em verdade, o conflito não apenas provocou a queda de $28 \%$ do PIB em 1998, mas seu efeito foi mais perene e alcançou a década seguinte, impossibilitando novas contratações de empréstimos externos necessários para viabilizar o financiamento dos projetos de desenvolvimento.

\subsection{Características gerais do setor agrícola guineense}

O setor agrícola mostrou-se ser o mais dinâmico desde a independência, tendo alcançado ainda em 1986 uma participação no PIB de 44\% (WORLD BANK DATA, 2015). A maior participação desse setor na composição do PIB é explicada pelo clima tropical muito favorável à plantação, por águas abundantes e terras muitos férteis que necessitam pouco de adubos químicos para gerar uma produção muito elevada (BARRY et al., 2007).

Houve a percepção do governo quanto à vantagem comparativa do setor agrícola guineense, e o objetivo das políticas de desenvolvimento sempre teve como palavra de ordem traçar uma modificação profunda no modo de produção local característico à época de um sistema de produção bastante rudimentar, ao qual o trabalho braçal ainda era predominante (HAVIK, 1990).

$\mathrm{O}$ resultado dessa ação foi promover as novas culturas, porque, na primeira década após a independência, o desempenho do setor agrícola dependia 
essencialmente da produção de alguns produtos específicos, tais como o amendoim e óleo de palma; já a partir de 1986 esses produtos deixaram de exercer principal papel na produção do setor, sendo substituídos principalmente pelo arroz e pela castanha de caju (Figura 1).

Segundo Catarino et al. (2015, p. 459), a castanha de caju é originária no Nordeste do Brasil e se espalhou para outros países das Américas do Sul e Central, chegando à África no final do século XVIII e, desde então, tem se tornado uma das atividades econômicas mais importantes, servindo como gerador de divisas, de modo que é difícil falar sobre o desenvolvimento de países como a Guiné-Bissau, por exemplo, sem considerar a cadeia de valor ou de produção do caju, visto que, nela, muitas famílias encontram fontes de emprego (LEA et al., 1990; CARVALHO e MENDES, 2015).

\subsubsection{A cultura e a cadeia de produção do caju}

A cultura do caju na Guiné-Bissau não é nova; nova é a velocidade com que sua produção aumentou na virada da década de 1980 para a de 1990 (MONTEIRO et al., 2017). Antes mesmo da independência, o caju já fazia parte das culturas voltadas para a subsistência das famílias e seu cultivo era predominante no interior do país, particularmente na região de Oio (BARRY et al., 2007). O bom desempenho de castanha de caju deve-se a reformas estruturas promovidas pelo PAE que, ao permitir a abertura econômica em 1986, aumentou o comércio internacional de produtos agrícolas. Em resposta ao aumento da demanda externa, o cultivo do cajueiro cresceu extensivamente e, desde 1995, estimava-se em cerca de 103 mil hectares a área destinada à exploração dos cajueiros e, em média, a cada ano, 10 mil novos hectares são incorporados à atividade, permitindo expandir a produção em torno de $20 \%$ ao ano (GUINÉ-BISSAU, 2005), marcando o aumento do grau da dependência da economia doméstica em relação ao desempenho dessa cultura, com sua representatividade no PIB doméstico crescendo de $4 \%$ em 1990, para 23\% em 2010 (FAOSTAT, 2015).

O boom do preço internacional desse produto em 1990 em resposta ao aumento da demanda dos países asiáticos, tais como Singapura e Índia, deu impulso a essa cultura. Com o preço mais favorável, tornou-se mais vantajoso às famílias produzirem e trocarem o valor da produção com o arroz (KYLE, 2009). A generalização dessa prática por todo o país fez da cultura do caju a principal geradora de emprego e, consequentemente, da renda. As estimativas recentes mostram que $85 \%$ da população do país está diretamente envolvida com o caju, sendo seu cultivo feito por pequenos agricultores, que ocupam $80 \%$ da plantação nacional (BARRY et al., 2007; FAOSTAT, 2015).

Atualmente, a plantação de cajueiro ocupa aproximadamente $6 \%$ do território nacional, ou seja, quase 210.000 hectares, e cada guineense produz mais de $53 \mathrm{~kg}$ de castanha de caju por ano, em média, isto é, mais de 90.100 toneladas são produzidas anualmente no país (GUINÉ-BISSAU, 2010).

Figura 1. Principais produções da Guiné-Bissau (1986-2010) em US\$ milhões

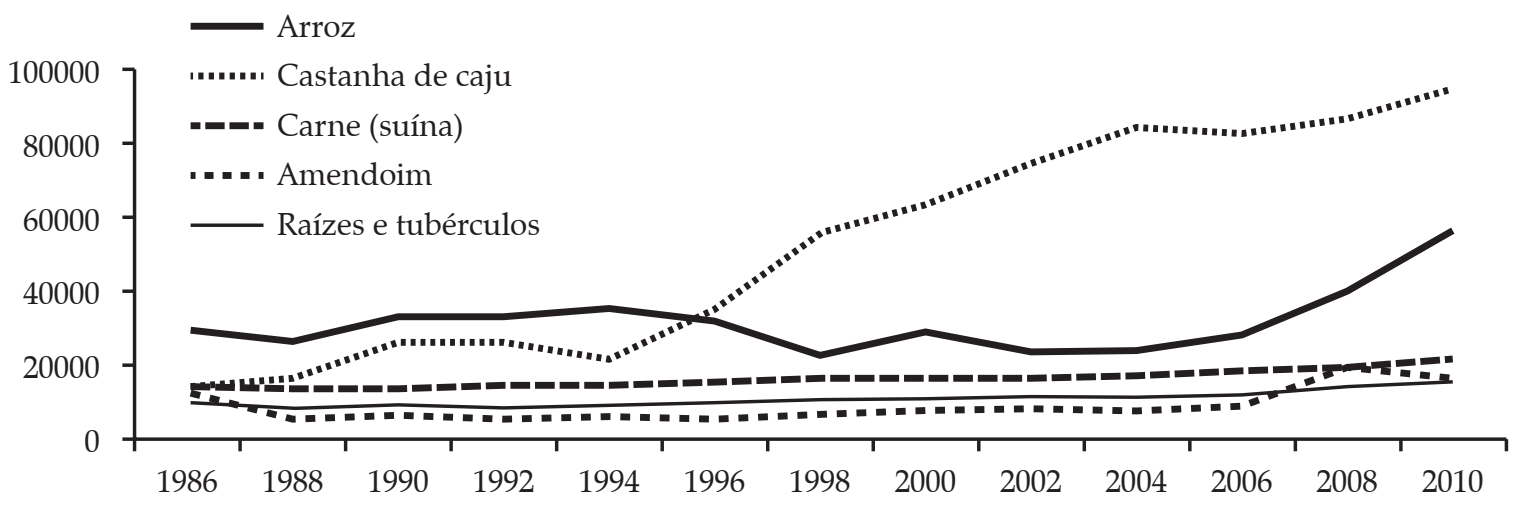

Fonte: Elaborada pelo autor a partir dos dados da Faostat. 
594 - Determinantes das Exportações de Castanha de Caju da Guiné-Bissau (1986-2011): uma análise sob a ótica do modelo de gravidade de Bergstrand

A cadeia de produção do caju é curta frente à da maioria dos produtos tropicais, cabendo destacar três fases principais, a saber: a fase de preparação de terreno, ou primeira fase; a fase da colheita, ou segunda fase, e a fase de comercialização, ou terceira fase (ver também CARVALHO e MENDES, 2015; CATARINO et al., 2015).

Primeira fase. Inicialmente, as famílias se organizam nas suas respectivas cidades ou comunidades e forma grupos ou cooperativas para trabalhar nas propriedades de cada um, fendendo as matas. O tempo necessário para a primeira fase geralmente é de dois a três meses, uma vez que só pode ocorrer durante a época da seca e porque as matas cortadas precisam ser queimadas antes do final de maio, que é o início da estação de chuva. Segundo Temudo e Abrantes (2014, p. 224), a plantação é feita colocando as sementes, geralmente obtidas de forma informal, em furos, e a distância entre árvores pode ser de $2 \mathrm{~m}$, devido à probabilidade de predação por esquilos.

Assim, nos primeiros dois anos, as terras preparadas não servem apenas para a plantação de caju, mas também são utilizadas para cultivar o amendoim, ou seja, nos primeiros 24 meses o cultivo das duas culturas ocorre simultaneamente e no mesmo terreno. Conforme cresce o cajueiro, as terras ficam menos propícias a qualquer outra cultura, sendo, portanto, reservadas apenas as atividades do caju. Nesta fase, as famílias passam cada outono limpando os terrenos para não serem tomados pelas matas que, de início, crescem mais rapidamente do que o cajueiro.

Segunda fase. A partir do terceiro ano, com a plantação em crescimento e o cajueiro dando frutas, durante o mês de abril de cada ano, iniciam-se as colheitas da castanha de caju que se estendem até ao final do mês seguinte. Agora, diferente da primeira fase, em que as famílias se organizam em cooperativas, na fase da colheita as famílias trabalham nas suas respectivas propriedades, ocorrendo casos de aqueles sem plantação irem trabalhar nas propriedades dos demais tendo a remuneração determinada pela quantidade de quilos de castanha por semana.

Terceira fase. Normalmente, o comércio do produto ocorre simultaneamente com a sua colheita. O comércio, ou "campanha de castanha de caju", é dividido em duas etapas. Primeiro, o governo estabelece um preço interno (preço ao produtor) por quilo de castanha de caju e esta informação chega aos produtores e aos comerciantes. No entanto, como não há nenhuma fiscalização por parte do governo em relação ao preço estabelecido, os comerciantes espalhados por diferentes regiões do país aproveitam esta situação e ofertam um preço mínimo por quilo, considerando uma margem entre este preço e o ofertado pelos demandantes externos. Com base nesse preço, a produção é comprada pelos comerciantes e vendida ao preço internacional no porto de embarque na capital do país. Assim, se inicia a segunda etapa do comércio deste produto, cujo retorno em divisas depende essencialmente do preço internacional (CATARINO et al., 2015).

Este estudo de Catarino et al. (2015) mostra que um cajueiro tem vida de 20 a 30 anos, com início de maior produção aos quatro anos, a depender da região. No sul da Guiné-Bissau este número reduz-se para dois anos, visto que é uma região mais propícia a qualquer tipo de cultura tropical. Já no norte, a fase de maturação do cajueiro é atingida aos cinco anos.

Kyle (2009) comenta que os cajueiros mais produtivos chegam a gerar uma média de $53 \mathrm{~kg}$ de castanhas por ano. Contabilizando com a sua idade mínima de 20 anos, isso implica que cada cajueiro é capaz de produzir, no mínimo de sua vida, uma quantidade de até $1.060 \mathrm{~kg}$ de castanha de caju.

Entretanto, o que se observa no modo de produção do caju em Guiné-Bissau é a técnica relativamente atrasada que as famílias utilizam para cultivar as terras. Estima-se que $99 \%$ das famílias ainda utilizem o trabalho braçal, tanto para fender as matas como durante o cultivo do cajueiro, ou seja, no processo de semear e da colheita. Além disso, a castanha de caju, por ser um produto extremamente inflável, e como não há um sistema de armazenamento interno suficiente para estocar a quantidade produzida, nem toda a produção é comercializada seja interna ou externamente, e o desperdício é crescente conforme aumenta o volume de produção.

\subsection{Mercado mundial de castanha de caju}

O mercado mundial de castanha de caju vem se expandido com a incorporação da cultura do caju em alguns países como uma das principais culturas agrícolas internas, refletindo no crescimento da sua produção mundial nas últimas décadas. Em 1986, o total da produção mundial do caju não superava 614.334 toneladas, mas, em 2011, mais países se engajaram no 
cultivo dos cajueiros, elevando este número para 5,18 milhões de toneladas por ano (FAOSTAT, 2015).

A castanha de caju é produzida em pelo menos 20 países, sendo a maioria deles pertencente a economias em desenvolvimento, destacadamente Índia, Vietnã, Brasil, Guiné-Bissau, Moçambique, Nigéria, Tanzânia, Indonésia, Tailândia, Malásia, Sri Lanka, Quênia, Filipinas, El Salvador, Guiné-Conacri, Costa do Marfim, Madagascar, Benin, Peru e Honduras. Até a década de 1990, os países asiáticos e africanos eram os mais representativos, dos quais Índia, Vietnã e Moçambique configuraram-se entre os principais produtores e ofertantes (Figura 2).

Durante a década de 1990, a participação indiana na produção mundial de castanha de caju continuou sendo predominante, mas a participação de países como Nigéria e Filipinas cresceu significativamente. Já em meados de 2005, o Vietnã tornou-se o principal produtor mundial, seguido da Nigéria e do Brasil.

Segundo Monteiro et al. (2017), os países da África subsaariana, em particular a região da África ocidental, contaram com mais de $45 \%$ da produção mundial de castanha de caju em 2015. Para eles, o aumento da plantação e produção do caju se deve principalmente a condições agroclimáticas altamente diversas que têm possibilitado a substituição das culturas alimentares tradicionais (como arroz, amendoim e sorgo) por culturas comerciais, tais como a do caju.

A castanha de caju é consumida principalmente nos países desenvolvidos, sendo os Estados Unidos o principal consumidor mundial desse produto em 2010 (Figura 3).

Figura 2. Principais produtores mundiais de castanha de caju (US\$ milhões) - 1990-2010

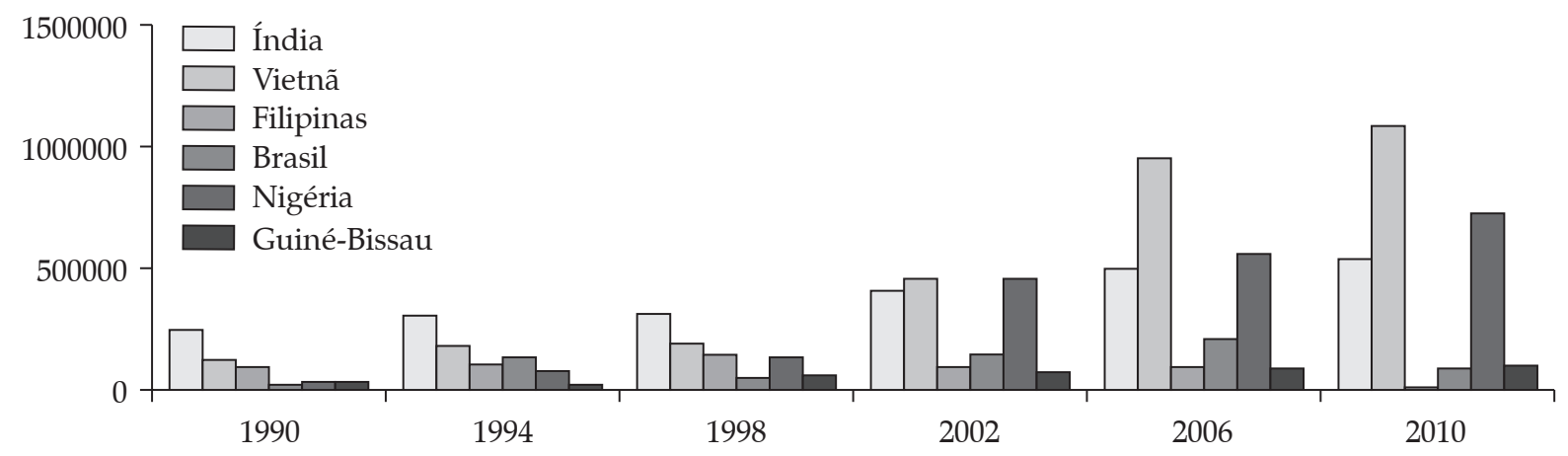

Fonte: Elaborada pelo autor com base nos dados da Faostat.

Figura 3. Principais consumidores da castanha de caju (em US\$ milhões) - 1986-2010

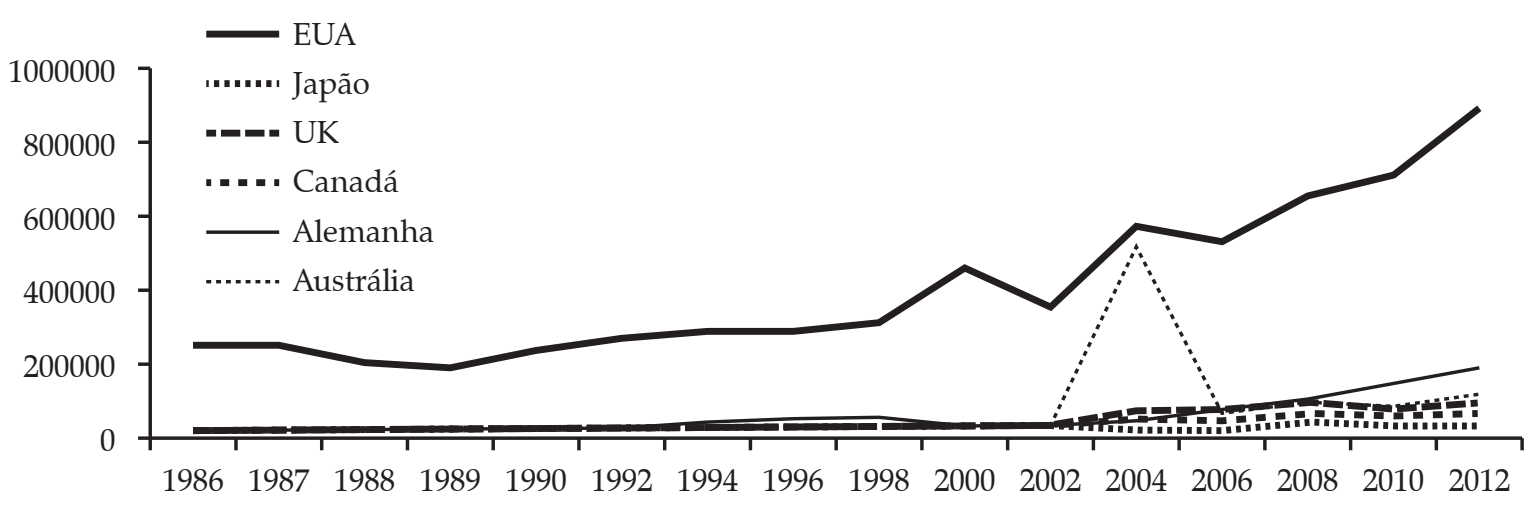

Fonte: Elaborada pelo autor com base nos dados da Faostat. 
596 - Determinantes das Exportações de Castanha de Caju da Guiné-Bissau (1986-2011): uma análise sob a ótica do modelo de gravidade de Bergstrand

A participação da Guiné-Bissau vem crescendo no mercado mundial de castanha de caju tanto em termos de produção quanto em comércio. Em termos de participação na produção mundial, o país cresceu de $2 \%$ em 1986 para 6\% em 2011. Por outro lado, no primeiro período (em 1986), a participação do país no comércio mundial situava-se em $5 \%$, subindo para $12 \%$ em 2011, tornando-se o segundo exportador mundial em 2011, com receita de US\$ 203,75 milhões, atrás apenas da Costa do Marfim, com exportações no valor de US\$263,59 milhões (FAOSTAT, 2015).

\section{Resultados e discussões}

Esta seção busca discutir os resultados do modelo econométrico acima descrito. Na primeira subseção, foram comparadas as três abordagens pooled, efeitos fixos e efeitos aleatórios, mediante os testes chow, LM e de Hausman. Na subseção 5.2 foi estimado o modelo completo, além de terem sido analisados os resultados e efetuado o comparativo com os resultados encontrados na literatura referentes à aplicação do modelo de gravidade para estimar as exportações desagregadas.

\subsection{Testes preliminares do modelo de gravidade}

Conforme o Quadro 1, o teste Hausman sugere a utilização do método de efeitos aleatórios em detrimento do método de efeitos fixos, pois a estatística calculada de Hausman é estatisticamente não significativa ao nível de significância de $5 \%$, possibilitando a não rejeição da hipótese nula. Pelo teste Chow/F também não se rejeitou a hipótese nula, sugerindo que o método pooled é o mais indicado para estimar o modelo de dados em painel da Equação 6 quando comparado com o método de efeitos fixos. Enquanto isso, a probabilidade do teste LM é próxima de 1, sendo estatisticamente insignificante, levando a não rejeitar a hipótese nula de que o pior método seja o de efeitos aleatórios comparativamente ao pooled.
Portanto, o modelo de gravidade apresentado anteriormente será estimado tendo por base o método pooled de dados em painel. Cheng e Wall (2005) comentam que a vantagem do método pooled é que se pode estimar o comércio bilateral por QMO utilizando os dados disponíveis de todos os anos. Embora tal procedimento não controle as características heterogêneas, Batalgi (2013, p.03-04) mostra que os dados em painel por si têm benefícios de controlar as heterogeneidades individuais por sugerir que firmas, estados ou países são heterogêneos.

Os dados pooled e o método de MQO são recorrentemente utilizados na estimação dos modelos de gravidade. Por exemplo, Sohn (2005) utilizou o modelo gravitacional para estimar o comércio de fluxos desagregados de 23 setores das economias da Coreia do Sul e da Coreia do Norte com base nos dados em painel. Para o autor, embora a maioria dos estudos que utilizam o modelo gravitacional se concentre em avaliar as exportações através de dados agregados, uma avaliação considerando níveis desagregados de exportações fornecem argumentos sólidos para o entendimento de como o volume de comércio diverge de setor para setor.

Escolhido o método pooled, neste trabalho, supõe-se que sejam válidas algumas das hipóteses no modelo de regressão linear clássico, como a não colinearidade perfeita entre os regressores, ausência de autocorrelação dos resíduos e da variância constante. Ambas as hipóteses são avaliadas ou testadas utilizando os procedimentos ou testes tradicionais.

A probabilidade do teste de Wooldridge é relativamente alta, o que leva a não rejeitar a hipótese nula, inferindo, assim, que não há autocorrelação de primeira ordem, ou seja, que as variáveis exógenas não contêm informações relevantes para a previsão do resíduo (Quadro 2).

Já os testes de White e de Breusch-Pagan/CookWeisberg sugeriram que a variância do erro condicionada aos valores dos regressores é constante ao longo dos anos, visto que as probabilidades dos testes são altas, levando, assim, a não rejeitar a hipótese nula de homoscedasticidade do modelo de painel.

Quadro 1. Testes preliminares para a escolha do modelo de dados em painel

\begin{tabular}{|c|c|c|}
\hline Teste Chow & Teste de Hausman & Teste LM \\
\hline Prob $>$ chi2 $=1,00$ & Prob $>$ chi2 $=0.9994$ & Prob $>$ Chi2 $=1,00$ \\
\hline Método de Estimação & MQO & MQO \\
\hline
\end{tabular}

Fonte: Resultados da pesquisa. Elaborada pelo autor. 
Quadro 2. Multicolinearidade e teste de autocorrelação e heteroscedasticidade dos resíduos

\begin{tabular}{|c|c|c|c|c|}
\hline \multicolumn{2}{|c|}{ Multicolinearidade } & \multicolumn{2}{|c|}{ Heteroscedasticidade } & Autocorrelação \\
\hline FIV & TOL & White & Breusch-Pagan/Cook-Weisberg & Wooldridge \\
\hline 3.597 & 0,278 & 0.5786 & 0.1222 & 0.1806 \\
\hline
\end{tabular}

Fonte: Resultados da pesquisa. Elaborada pelo autor.

O FIV de 3.60 sugere que os regressores não são colineares de forma perfeita, pois tal valor fornece um TOL de 0.278 , distante de zero.

Assim, os testes preliminares sugeriram a utilização dos dados pooled para estimar o modelo de gravidade homoscedástico. A subseção seguinte apresenta as estimativas do modelo estimado mediante a utilização do método de MQO.

\subsection{Estimação e interpretação do modelo de gravidade}

Em cada linha ou coluna da Tabela 1, os valores fora de parênteses são os coeficientes ou as estimativas dos parâmetros do modelo e os valores entre parênteses são os seus respectivos erros padrão. $\mathrm{O}$ p-valor é apresentado na coluna 3 .

Os resultados do modelo mostram que as variáveis câmbio e rendas brutas apresentam coeficientes estatisticamente significativos, enquanto as rendas per capita e a distância são insignificantes do ponto de vista estatístico. A renda bruta da Guiné-Bissau, lnpibgb, é significativa ao nível de significância de $5 \%$, enquanto a renda bruta da Índia, lnpibind, e a taxa de câmbio, lncambio, são significativas em até $1 \%$ de significância.
A reação do volume de exportação de castanha de caju destinada para a Índia é mais que proporcional à variação de renda bruta da Guiné-Bissau. Assim, considerando tudo o mais constante, um aumento de $1 \%$ da renda bruta da Guiné-Bissau gera aumento de 1,159 ponto percentual no volume de comércio bilateral de castanha de caju.

No mesmo período, variando a renda por indivíduo em $1 \%$ na Guiné-Bissau, o comércio bilateral de castanha de caju aumentaria em 0,176 ponto percentual, sendo esta reação inferior às reações de exportações em relação à variação da renda nacional bruta.

Quanto à renda externa, o modelo de gravidade sugere que, se a renda da Índia variar, a parcela da renda adicional decorrente dessa variação será destinada à compra de castanha de caju da Guiné-Bissau. Assim, uma variação de $1 \%$ da renda bruta daquele país gera aumento de 0,87 ponto percentual do volume de exportações de castanha de caju guineense para o mercado indiano.

Entretanto, a variação da renda per capita da Índia não teria os mesmos efeitos que a variação da sua renda nacional bruta, uma vez que, se a renda per capita aumentar $1 \%$, as exportações dirigidas para a Índia aumentariam apenas 0,0237 ponto percentual,

Tabela 1. Resultados do modelo de gravidade

\begin{tabular}{lcc}
\hline \multicolumn{1}{c}{ Variável/Modelo } & Pooled com heteroscedasticidade em grupo & P-Valor \\
\hline lnpibgb & $1.159(0.487)^{*}$ & 0,022 \\
lnpibind & $0.870(0.144)^{* *}$ & 0.000 \\
lnpibpergb & $0.176(0.718)$ & 0.807 \\
lnpibperind & $0.023(0.124)$ & 0.850 \\
Lndist & $-0.148(0.224)$ & 0.551 \\
lncambio & $1.729(0.363)^{* *}$ & 0.000 \\
Constante & $-16.364(3.427)$ & 0.000 \\
SQR & 14.274 & \\
Número de grupo & 2 & \\
$\mathrm{R}^{2}$ & 0.721 & \\
Observações & 52 & \\
Método de estimação & $\mathrm{MQO}$ & \\
Nota: * Significativo a 5\%; ** Significativo a 1\%. & & \\
Fonte: Resultados da pesquisa. Elaborada pelo autor. & &
\end{tabular}

RESR, Piracicaba-SP, Vol. 56, № 04, p. 583-604, Out./Dez. 2018 - Impressa em Janeiro de 2019 
598 - Determinantes das Exportações de Castanha de Caju da Guiné-Bissau (1986-2011): uma análise sob a ótica do modelo de gravidade de Bergstrand

indicando que, se houver elevação de renda por indivíduo na Índia, estes indivíduos vão destinar uma parcela maior da sua renda transitória para outros gastos e apenas destinam uma pequena fração para a compra de castanha de caju da Guiné-Bissau.

Enquanto isso, as exportações reagem positivamente a variações de câmbio. Em verdade, o coeficiente associado a variável câmbio não somente é altamente significativo bem como é positivo e com a elasticidade mais que proporcional, ou seja, as exportações aumentariam quase que o dobro de variação cambial, visto que uma variação de $1 \%$ da taxa de câmbio provocaria uma variação de 1,729 ponto percentual no volume de exportações de castanha, sugerindo que uma desvalorização seria uma política capaz de intensificar o comércio bilateral de castanha de caju.

Por outro lado, uma distância maior teria efeitos negativos para o comércio de castanha de caju, isto é, o volume de exportações diminuiria se os dois centros comerciais fossem distantes um do outro. Por isso, a elasticidade de distância é negativa, indicando que, se o custo de transporte aumentar $1 \%$, as exportações diminuíram em 0,148 ponto percentual.

Em geral, as variáveis independentes (rendas, distância e câmbio) explicam, em conjunto, mais de $72 \%$ do comércio bilateral de castanha de caju guineense no período de 1986 a 2011.

A maioria dos coeficientes obtidos é estatisticamente significativa ao nível de $5 \%$, podendo assim dizer que há robustez nas estimativas do modelo de gravidade de Bergstrand (1985) aplicado para avaliar as exportações de castanha de caju da Guiné-Bissau para a Índia, já que o comportamento das exportações mostrou ser elástico a alterações de todas as variáveis explanatórias do modelo (rendas, distância e câmbio). Além disso, os resultados reportados no presente estudo são robustos quando comparados com os encontrados na literatura (Tabela 2) e satisfazem também os pressupostos básicos do modelo de gravidade, segundo os quais quanto maior os tamanhos dos mercados e as estruturas produtivas dos países engajados no comércio, maior a possibilidade de esses países aumentarem o intercâmbio comercial entre si, indicando também que as dificuldades de comércio aumentam com a distância dos centros comerciais.

Bergstrand (1985) encontrou as respectivas elasticidades-renda brutas dos países exportador e importador de 0.75 e 0.53 ; já nos resultados do modelo de gravidade de Baier e Bergstrand (2007), tais elasticidade são de 1.18 e 0.98 . As elasticidades-renda brutas e da distância reportadas pelo presente estudo encontram-se relativamente mais próximas ao estudo de Baier e Bergstrand (2007) e Zhu e Gu (2008) do que ao de Bergstrand (1985). Porém, os sinais apresentados pelos coeficientes das variáveis são semelhantes aos encontrados por ambos os autores.

O presente estudo diverge tanto na magnitude das variáveis como nos seus sinais com o estudo realizado por Hatab et al. (2010) sobre o comércio bilateral do Egito, com exceção da elasticidade-renda do país importador (0.74), considerada próxima à encontrada neste estudo (0.869). A elasticidade de renda do país importador é $4.569 \%$ maior que a reportada para o comércio bilateral de castanha de caju e as elasticidades-rendas per capita não estão de acordo com os pressupostos do modelo, pois, em Hatab et al. (2010), tais variáveis influenciam negativamente o comércio.

Tendo por base o modelo de gravidade estimado, é relevante abordar o resultado de cada uma

Tabela 2. Análise de sensibilidade: comparação com os estudos revistos

\begin{tabular}{|c|c|c|c|c|c|c|c|c|}
\hline Autor & Renda $i$ & Renda $j$ & $\begin{array}{c}\text { Renda } \\
\text { per capita } i\end{array}$ & $\begin{array}{c}\text { Renda } \\
\text { per capita } j\end{array}$ & $D_{i j}$ & $A_{i j}$ & Câmbio & MQO \\
\hline Baier e Bergstrand (2007) & $\begin{array}{c}1.18 \\
(104.13) \\
\end{array}$ & $\begin{array}{c}0.98 \\
(87.39) \\
\end{array}$ & & & $\begin{array}{c}-1.17 \\
(-32.57) \\
\end{array}$ & $\begin{array}{c}0.29 \\
(2.85) \\
\end{array}$ & & Pooled \\
\hline Hatab et al. (2010) & $\begin{array}{l}5.728 \\
(3.59) \\
\end{array}$ & $\begin{array}{l}0.740 \\
(7.40) \\
\end{array}$ & $\begin{array}{l}-5.781 \\
(-3.48) \\
\end{array}$ & $\begin{array}{l}-0.813 \\
(-0.64)\end{array}$ & & $\begin{array}{l}-1.112 \\
(-3.96)\end{array}$ & $\begin{array}{l}-0.039 \\
(-0.52)\end{array}$ & Pooled \\
\hline Zhu e Gu (2008) & $\begin{array}{c}0.881 \\
(0.361) \\
\end{array}$ & $\begin{array}{c}0.859 \\
(0.361) \\
\end{array}$ & $\begin{array}{c}2.585 \\
(0.462) \\
\end{array}$ & $\begin{array}{l}1.966 \\
(0.462) \\
\end{array}$ & $\begin{array}{l}-0.247 \\
(0.585) \\
\end{array}$ & $\begin{array}{l}-2.321 \\
(0.564) \\
\end{array}$ & & Pooled \\
\hline Estudo atual & $\begin{array}{c}1.159 \\
(0.487)\end{array}$ & $\begin{array}{c}0.869 \\
(0.144)\end{array}$ & $\begin{array}{c}0.223 \\
(0.718)\end{array}$ & $\begin{array}{c}0.024 \\
(0.124)\end{array}$ & $\begin{array}{l}-0.162 \\
(0.224)\end{array}$ & & $\begin{array}{c}1.729 \\
(0.363)\end{array}$ & Pooled \\
\hline
\end{tabular}

Nota: Renda $i$ e renda $j$ são as rendas dos países exportador e exportador, respectivamente. $D_{i j}$ é a distância de $i$ para $j$ e $A_{i j}$ é a variável $d u m m y$ que indica a existência de acordos de comércio entre os países $i$ e $j$.

Fonte: Elaborada pelo autor com base nos estudos dos autores acima representados e do presente estudo. 
das variáveis frente à peculiaridade da economia guineense. Dito isto, uma possível explicação no que se refere à maior sensibilidade das exportações à variação da renda bruta da Guiné-Bissau do que a variações de sua renda per capita pode ser entendida considerando os efeitos da política no pós-independência. Desde a década de 1980, o setor agrícola sempre foi o setor de vantagens comparativas da economia guineense, sendo todos os esforços de desenvolvimento voltados para promover a sua modernização, visando aumentar a produção e aproveitar os ganhos de comércio através do aumento do volume de exportações de produtos do primeiro setor (sobre as estratégias de modernização do setor agrícola no pós-independência, ver HAVIK, 1990). Assim, o setor industrial deixou de receber os incentivos, exceto no início da década de 1980, quando a necessidade especial de promover as exportações agrícolas com maior valor adicionado levou à criação do complexo industrial de Cumeré, que nem entrou em funcionamento pleno devido aos problemas técnicos enfrentados pelas empresas que ali operavam.

Portanto, a ação do governo a partir de 2000 e o objetivo da política de desenvolvimento da economia guineense estavam atrelados ao quadro dos objetivos de desenvolvimento do milênio das nações unidas, direcionado especialmente para combater a fome e a pobreza extrema.

Deste modo, os fatores conjunturais, como o Conflito Civil de 1998, e os fatores estruturais, tais como a instabilidade institucional, conjugados à orientação histórica e política econômica do país, voltada especialmente para a modernização do setor agrícola, criavam uma defasagem muito grande entre a demanda interna e a oferta de determinados bens, particularmente aqueles industrializados. Assim, espera-se que, se a renda per capita aumentar, as pessoas poderão utilizar uma fração dessa renda para comprar (seja importando) os bens que necessitam, mas que anteriormente não conseguiriam adquirir devido à restrição da oferta doméstica, em vez de comprar a quantidade adicional de castanha de caju. Isto pode indicar porque a elasticidade de exportação de castanha de caju em relação à renda per capita é relativamente baixa quando comparada com a elasticidade de exportações em relação à renda bruta, o que parece ser consistente para explicar os padrões de comércio entre dois países em desenvolvimento. Conforme Fieler (2011), a renda per capita aumenta mais o volume de comércio entre os países desenvolvidos do que entre países em desenvolvimento, ou seja, a renda bruta é um vetor mais capaz de influenciar as exportações do que as rendas per capita.

Há variadas razões pelas quais o aumento do volume de comércio bilateral de castanha de caju é mais que proporcional à variação da renda bruta, cabendo destacar duas: (i) o tamanho de mercado e (ii) a estrutura produtiva. Segundo Sohn $(2005$, p. 11), os países com o tamanho de mercado grande tornam-se autossuficientes porque são capazes de absorver uma parte maior da produção com o aumento da dimensão económica e, neste caso, o aumento do comércio bilateral é menos proporcional ao aumento do PIB. Já os países com tamanho de mercado pequeno dispenderiam uma proporção maior de sua renda na compra do bem exportado, fazendo com que o aumento do comércio bilateral seja mais que proporcional ao aumento do PIB. Enquanto isso, países com a estrutura produtiva diversificada geralmente têm maiores capacidades de atender uma gama maior de demanda do que países com a estrutura produtiva menos diversificada. Mccallum (1995, p. 621) mostra que é válida a predição da teoria padrão de comércio internacional segundo a qual o comércio é positivamente relacionado ao grau das estruturas de produção.

Quanto à sensibilidade do volume de exportações à renda bruta da Índia, pode-se dizer que a expansão das rendas em países emergentes vem sendo acompanhada pelo aumento da demanda por insumos para sustentar as taxas de crescimento das suas economias, que atingiram médias expressivas nos últimos anos. A Índia é um caso especial desses países, cuja taxa média de crescimento econômico é de aproximadamente $8 \%$ ao ano desde o início dos anos 2000 até os atuais. Como resultado, não apenas aumentaram seus investimentos externos para os países africanos, mas também conseguiram integrar-se nas cadeias de fornecedores globais em busca de bens intermediários ou de insumos básicos para viabilizar a sua produção interna. Em relação à Guiné-Bissau, este fenômeno é explicado pelo volume de exportação de castanha de caju para aquele país asiático.

Entretanto, assim como o volume de comércio bilateral de castanha de caju é mais sensível à variação da renda bruta da Guiné-Bissau do que à sua renda per capita, o mesmo também se verifica para o caso da Índia, ou seja, a sensibilidade-renda bruta da Índia ao volume de comércio é maior do que à sensibilidade-renda per 
600 - Determinantes das Exportações de Castanha de Caju da Guiné-Bissau (1986-2011): uma análise sob a ótica do modelo de gravidade de Bergstrand

capita desse país. Por efeito, tudo o mais constante, a renda bruta é $0,845 \%$ mais elástica do que a renda per capita para explicar o aumento de $1 \%$ do volume de comércio de castanha de caju. Isto sugere que a dimensão da economia da Índia explicaria mais o comércio deste produto do que o aumento da renda por habitante.

Quanto à distância, como há substituição dos bens no consumo, o coeficiente negativo diz que os consumidores da Índia, ao se depararem com aumento de preço de castanha de caju, interpretarão isso como o aumento do custo de vida e, consequentemente, passarão a adquirir uma quantidade cada vez menor. Os vendedores, por sua vez, ao se depararem com a queda da demanda por seu produto em função do preço estabelecido para compensar os efeitos dos custos de transporte, eles passarão a reagir maiores distâncias, diminuindo a demanda por produtos cujo custo de transporte é elevado o suficiente para diminuir a demanda interna por seus produtos. Sendo assim, espera-se que a distância seja um vetor capaz de reduzir a demanda por castanha de caju guineense, o que é consistente também com os estudos empíricos aplicando o modelo de gravidade estendido para avaliar a magnitude dos parâmetros que influenciam o comércio entre os países ou regiões.

\section{Considerações finais}

O presente estudo procurou evidenciar, por meio de um modelo de gravidade, os determinantes de exportações de castanha de caju da Guiné-Bissau para a Índia no período de 1986-2011. Além das variáveis recorrentemente utilizadas pelos estudos seminais na literatura econômica acerca dos modelos gravitacionais, a equação de gravidade de Bergstrand aqui utilizada permitiu elencar um conjunto mais amplo de variáveis, tais como as rendas brutas e per capita, os preços relativos e a distância.

Utilizando os dados em painel e com base no método de mínimos quadrados ordinários (MQOPooled), um modelo econométrico gravitacional foi estimado. Nele, foi confirmada a premissa básica da equação de gravidade de comércio bilateral, segundo a qual os fluxos de comércio reagem positivamente a um conjunto limitado das variáveis econômicas, como os tamanhos dos mercados e as estruturas produtivas, e negativamente à distância entre os centros comerciais de pares de países engajados no comércio. Contudo, apenas algumas hipóteses iniciais foram confirmadas, mas muitas outras não se confirmaram, já que os coeficientes das rendas per capita e da taxa de câmbio foram estatisticamente insignificantes.

Apesar disso, em um cenário comparativo, pode-se dizer que há robustez nos resultados aqui obtidos, porque estes convergem tanto em sinais quanto na magnitude dos parâmetros com vários estudos revistos.

Portanto, com base nesses resultados, sugere-se que a forma pela qual o país se inseriu no comércio internacional, com apenas um único produto importante para a geração de divisas e de emprego, naturalmente, o coloca em uma situação de vulnerabilidade externa, visto que as exportações do país dependem muito da magnitude da renda externa. Assim, uma política nacional de comércio voltada para definir um nível ótimo da taxa de câmbio pode servir para estimular as exportações, não apenas para o mercado indiano, mas também para novos mercados consumidores, diminuindo os efeitos das flutuações da renda da Índia sobre as exportações guineenses.

As divisas provenientes das exportações de castanha de caju para diferentes mercados podem ser alocadas não apenas para o financiamento das despesas públicas, mas principalmente para a promoção do setor industrial interno voltado para o processamento de castanhas, possibilitando a geração de maior valor agregado ao produto. Incialmente, os demais setores industriais normalmente crescerão em função do dinamismo trazido pelo seu principal produto de produção e gerador de divisas. Contudo, a confirmação dessa hipótese requer estudos mais detalhados. O que se tem nos resultados deste trabalho é um indício dos respectivos impactos positivos e negativos das estruturas das economias e da distância sobre o comércio de castanha de caju. No plano interno, será necessário entender como o desenho da situação institucional presente em Guiné-Bissau vem contribuindo para o desenvolvimento econômico do país. Quanto ao modelo, serão requeridos estudos mais aprofundados, inclusive introduzindo mais variáveis presentes nos de Geraci e Prewo (1977), Polder e Meijeren (2000) e Anderson e Wincoop (2003), Fally (2015) e Egger e Nigai (2015), tais como línguas, efeitos fronteiras, barreiras sanitárias, outros custos de comercialização etc. 


\section{Referências}

AITKEN, N. D. The effect of the EEC and EFTA on European Trade: a Temporal Cross-Section Analysis. The American Economic Review, v. 5, p. 881-892, dec. 1973.

ALVESSON, M. e ZEJAN, M. Guiné-Bissau: o impacto do Programa de Ajustamento Estrutural sobre o bemestar dos pequenos proprietários rurais. Soronda, INEP, n. 11, p. $81-104,1991$.

ANDERSON, J. E. e WINCOOP, E. V. Gravity with Gravitas: a Solution to the Border Puzzle. American Economic Review, v. 93, n. 1, p. 170-192, 2003.

BAIER, S. L. e BERGSTRAND, J. H. Do free trade agreements actually increase members' international trade? Journal of International Economics, v. 71, n. 1, p. 72-95, 2007.

BALTAGI, D. H. Econometric analysis of panel data. New York: Willey, 2013.

BARRY, B. S., CREPPY, E. e WODON, Q. Cashew Production, Taxation, and Poverty in Guinea-Bissau. World Bank Working Paper, p. 77-88, Jan. 2007. Disponível em: < https://mpra.ub.uni-muenchen.de/11181/1/GB Conflict6.pdf>. Acesso em: 24 jun. 2015.

BCEAO. Banco Central dos Estados da África Ocidental. Dados da taxa de câmbio. Disponível em: $<$ http://edenpub.bceao.int>. Acesso em: 5 jan. 2015.

BERGSTRAND, J. H. The gravity equation in international trade: some microeconomic foundations and empirical evidence. The Reviews of Economics and Statistics, v. 67, n. 4, p. 474-481, ago. 1985.

The Generalized Gravity Equation, Monopolistic Competition, and the Factor Proportions Theory in International Trade. The Reviews of Economics and Statistics, v. 71, n. 1, p. 143-153, 1989.

BIKKER, J. A. An extended gravity model with substitution applied to international trade. Tjalling C. Koopmans Research Institute. Discussion Paper Series, n. 215, 30p.; 2009. Disponível em: <http://www.uu.nl/ sites/default/files/rebo_use_dp_2009_09-17.pdf > . Acessoem: 12 fev. 2015.

BRADA, J. C. e MÉNDEZ, J. A. Economic integration among developed, developing and centrally aplanned economies: a comparative analysis. The Reviews of Economics and Statistics, v. 67, p. 549-556, ago. 1985.

CÁ, O. L. A Construção da Política do Currículo na GuinéBissau e o Mundo Globalizado. Cuiabá, MT: UFMT, 2008.
CARVALHO, B. R. P. e MENDES, H. Cashew Chain Value in Guiné-Bissau: Challenges and Contributions for Food Security: a Case Study for Guiné-Bissau. Int. J. Food System Dynamics, v. 7, n. 1, p. 1-13, 2015.

CASTILHO, M. R. O acesso das exportações do mercosul ao mercado europeu. Pesquisa e Planejamento Econômico, v. 32, n. 1, p. 149-198, abr. 2002.

CATARINO, L., MENEZES, Y. e SARDINHA, R. Cashew cultivation in Guinea-Bissau - risks and challenges of the success of a cash. Scientia Agricola, v. 72, n. 5, p. 459467, 2015.

CHENG, I-H. e WALL, H. J. Controlling for Heterogeneity in Gravity Models of Trade and Integration. The Federal Reserve Bank of ST. Louis, v. 87, n. 1, p. 49-63, 2005.

COELHO, D. J. Formulação em Programação Matemática do Modelo Gravitacional e sua Interpretação Econômica. Working Paper, n. 2, p. 01-45, 1983.

DEARDORFF, A. V. Determinants of Bilateral Trade: Does Gravity Work in a Neoclassical World? In: JEFFREY, V. e FRANKEL, A. (Eds.). National Bureau of Economic Research: The Regionalization of the World Economy, 1998.

EGGER, P. e NIGAI, S. Structural gravity with dummies only: constrained ANOVA-type estimation of gravity models. Journal of International Economics, v. 97, p. 86-99, 2015.

EICHENGREEN, B. e IRWIN, D. A. The Role of History in Bilateral Trade Flows, 56p, 1998. Disponível em: < http:// www.nber.org/chapters/c7819.pdf>. Acesso em: 12 jan. 2015.

EL-ARISH, M. A. A Gravity Model Analysis of Egypt's Trade and Some Economic Blocks. International Conference on Applied Life Sciences, p. 343-350, set. 2012. Disponível em: <http://cdn.intechopen.com/ pdfs-wm/39918.pdf>. Acesso em: 21 abr. 2015.

FALLY, T. Structural gravity and fixed effects. Journal of International Economics, v. 97, p. 76-85, 2015.

FAOSTAT. Food and Agriculture Organization of the United Nations. Dados sobre produção, preço e exportação de castanha de caju. Disponível em: <http://faostat.fao. org/site/342/default.aspx> . Acesso em: 5 jan. 2015.

FARIAS, J. J. e HIDALGO, A. B. Comércio Interestadual e Comércio Internacional das Regiões Brasileiras: uma Análise Utilizando o Modelo Gravitacional. Documentos Técnico-Científicos, v. 43, n. 2, p. 252-265, abr.jun. 2012. 
602 - Determinantes das Exportações de Castanha de Caju da Guiné-Bissau (1986-2011): uma análise sob a ótica do modelo de gravidade de Bergstrand

FEENSTRA, R. C., MARKUSEN, J. A. e ROSE, A. K. Using the gravity equation to differentiate among alternative theories of trade. Canadian Journal of Economics, v. 34, p. 430-447, 2001.

FIELER, A. C. Nonhomotheticity and bilateral trade: evidence and a quantitative explanation. Econometrica, v. 79, n. 4, p. 1069-1101, jul. 2011.

GERACI, V. J. e PREWO, W. Bilateral trade flows and transport costs. The Review of Economics and Statistics, v. 59, n. 1, p. 67-74, fev. 1977.

GREENE, W. H. Econometric analysis. New Jersey: Prentice HALL, 1993.

GUINÉ-BISSAU. Documento de Estratégia Nacional de Redução da Pobreza (I DENARP), 2005. Disponível em: $<$ http://www.stat-guinebissau.com/denarp/denarp. pdf > . Acesso em: 12 jun. 2015.

- Para além de Castanha de Caju: diversificação através do comércio, 2010. Disponível em: <http:// wwwwds.worldbank.org/external/default/ WDSContentServer/WDSP/IB/2011/02/10/000333038_2 0110210233340/Rendered/PDF/595620ESW0PORT1M ain0Report01PUBLIC1.pdf>. Acesso em: 5 dez. 2014.

GUJARATI, D. N. e PORTER, D. C. Econometria básica. 5. ed. Mac Graw Hill, 2011.

HARRIS, M. N. e MÁTYÁS, L. The econometric of Gravity Model. Melbourne Institute. Working Paper, n. 5, 18p., 1998.

HATAB, A. A., ROMSTAD, E. e HUO, X. Determinants of egyptian agricultural exports: a gravity model approach. Modern Economic, v. 1, p. 134-143, 2010.

HAVIK, P. J. A pesquisa sobre a transformação rural na Guiné-Bissau: breve inventário de temas e autores após a independência. Soronda, INEP, n. 10, p. 41-58, 1990.

HSIAO, C. Analysis of Panel Data. New York: Cambridge University Press, 2003.

KOKKO, A. e TINGVALL, P. G. The Eurovision Song Contest, Preferences and European Trade. Ratio Institute Working Paper, n. 183, 30p.; Sweden, 2000. Disponível em: <http://ratio.se/app/uploads/2014/11/ ak_pt_eurovision_183.pdf > . Acesso em: 13 jan. 2015.

KYLE, S. Cashew Production in Guinea Bissau. Working Paper. Warren hall. Jul. 2009.

LEA, J. D., HUGO, C. e CARDOSO, C. A Review of the Cashew Sub-Sector in Guinea Bissau. Agency for International Development. United States Department of State. FFGI e INEP, Report n. 119, 49p, 1990.
LINNEMANN, H. An Econometric Study of International Trade Flows. Review by: PRAIS, S.J. The American Economic Review, v. 57, n. 1, p. 283-285, 1967.

MCCALLUM, J. National borders matter: Canada-U.S: regional trade patterns. The American Economic Review, v. 85, n. 3, p. 615-623, 1995.

MENDES, R. e JAWAD, M. Breve análise do setor comercial. Ministério do Plano e Cooperação Internacional, Gabinete de Estudos Econômicos, ano II, n. 2, p. 13-22, jun. 1986.

MONTEIRO, F. et al. Cashew as a High Agricultural Commodity in West Africa: Insights towards Sustainable Production in Guinea-Bissau. Sustainability, v. 9, n. 1666, 2017.

OGULEDO, V. I. e MACPHEE, C. Gravity models: a reformulation and an aplication to discriminatory trade arrangements. Applied Economics, n. 26, p. 107120, 1994.

PADOVANI, F. O programa de Ajustamento na GuinéBissau e a discussão de um modelo. Soronda, INEP, n. 11, p. 55-64, 1991.

POLDER, J. M. e MEIJEREN, J. V. Modeling and forecasting international trade flows. NEA TransportResearchand Training, Rijswijk-ZH, p. 185-198, 2000.

SANHÁ, I. Guiné-Bissau: Programa de Ajustamento Estrutural. Boletim de informação sócio-econômica, ano 3, p. 37-52, abr. 1988.

SANSO, M., CUAIRAN, R. e SANZ, F. Bilateral trade flows, the gravity equation, and functional form. The Review of Economics and Statistics, v. 75, n. 2, p. 266-275, 1993.

SEVELA, M. Gravity-type model of Czech agriculture export. Agriculture Economy, v. 48, n. 10, p. 463-466, 2002.

SOHN, C-H. Does the Gravity Model Fit Korea's Trade Patterns? Implication for Korea's FTA Policy and NorthSouth Korean Trade. Center for International Studies, Working Papers, 2005. Disponível em: <http://www. econ.ynu.ac.jp/cits/publications/pdf/CITSWP2005-02. pdf>. Acesso em: 24 jul.2015.

STEWART, J. Q. Demographic gravitation: evidence and applications. Sociometry, v. 11, n. 1/2, p. 31-58, 1948.

STOCK, J. H. e WATSON, M. Econometria. São Paulo: Person Education, 2004.

TEMUDO, M. P. e ABRANTES, M. The Cashew Frontier in Guinea-Bissau, West Africa: Changing Landscapes 
and Livelihoods. Springer Science+Business, n. 42, p. 217-230, 2014.

TINBERGEN, J. et al. Shaping the world economy; suggestions for an international economic policy. Books (Jan Tinbergen), Twentieth Century Fund, New York, 1962.

TVEDTEN, I. Programs de ajustamento estrutural e implicações locais: o caso dos pescadores artesanais na Guiné-Bissau. Soronda, INEP, n. 11, 1991, p. 65-80, 1991.

UNCTAD. United Conference on Trade and Development. Dados sobre rendas. Disponível em: < http://unctadstat.unctad.org/wds/TableViewer/ tableView.aspx?ReportId=96>. Acesso em: 05 jan. 2015.

USDA. United States Department of Agriculture. Dados sobre distância. Disponível em: < http://www.usda.gov/ wps/portal/usda/usdahome>. Acesso em: 11 jun. 2015.
WALL, H. J. Using the gravity model to estimate the costs of protection. Federal Reserve Bank of St. Louis Review, p. 33-40, 1999.

WITS - World Integrated Trade Solution. Informações sobre o comércio bilateral. Disponível em: < http://wits. worldbank.org/countrysnapshot/GNB $>$. Acesso em: 20 jun. 2015.

WORLD BANK DATA. World Bank. Informações sobre o comércio - importações e exportações como proporção do PIB. Disponível em: < http://data. worldbank.org/>. Acesso em: 20 de maio de 2015.

ZARZOSO, I. M. e LEHMANN, F. N. Augmented gravity model: an empirical application. Journal of Applied Economics, v. VI, n.0 2, 291-316, n 2003.

ZHU,H. e GU.H. China-US Border Effect of Agricultural Trade Using Gravity Model. Shanghai, p. 891-900, 2008. Disponível em: < http://dl.ifip.org/db/conf/ifip12/ ccta2008-2/ZhuG08.pdf>. Acesso em: 29 jul. 2015.

Todo o conteúdo deste periódico, exceto onde estiver identificado, está licenciado sob uma Licença CreativeCommons (ccby 4.0). 
